\title{
The Slope Shape of Loose Accumulation Body Effect Analysis of Subgrade Slope Stability
}

\author{
Yajun Xiao ${ }^{1, a)}$, Xuesong $\mathrm{Mao}^{1, \mathrm{~b})}$, and Jian $\mathrm{Li}^{1, \mathrm{c})}$ \\ ${ }^{1}$ School of Chang An University, Shanxi 710064, China. \\ a)276908628@qq.com, ${ }^{\text {b) }}$ xuesongxian@aliyun.com, ${ }^{\text {c) } 1670513582 @ q q . c o m}$
}

Keywords: Slope shape, Loose accumulation, Stability

\begin{abstract}
Based on the Sichuan-Tibet highway south line (Tibet border line of State Road 318 K3473+ 000-K4670+000 and K1324+000-K1473+000 National Highway 214 line) the survey results, using Midas/GTS to establish the numerical model of slope stability analysis,analysis of two slope loose accumulation effect of subgrade slope stability. In the condition of respectively change the upper and lower slope,weanalyzes the change trend of subgrade slope safety coefficient of loose body accumulation. The simulation results show that the classification of slope stability can obviously improve the slope. Compared to the the slope change for the influence of the safety factor of the upper slope, resulting in lower slope safety coefficient of slope change is more obvious.
\end{abstract}

\section{INTRODUCTION}

The Sichuan Tibet highway (Tibet territory) along with the distribution of a large number of loose deposits [1]. The slope may result in landslide, collapse, debris flow on slope and other highway disasters [2]. Therefore, improving the stability of slope of loose accumulation, to prevent highway disasters, strengthen the crucial role of highway operation safety. The loose accumulation slope research focused on the influence of external environment on the stability of Zhang Jiqing [3]. The analysis of water content, stone content, effect of compaction on the loose accumulation slope instability mechanism. The deformation mechanism of Zhao Jianjun [4] by using two-dimensional finite element on the slope. Miu Haibo [5] discussed the evolution characteristics under homogeneous condition of extreme ice and snow disaster the slope of the field.

The slope is an important factor affecting the slope stability of loose accumulation, this paper based on the Sichuan Tibet highway south line (Tibet border line of State Road 318 K3473+000-K4670+000andK1324+000-K1473+000NationalHighway214line) the field investigation, using Midas/GTS to establish the numerical model, analysis of two slope loose accumulation effect of subgrade slope stability, and summed up the regularity of the effect.

\section{MIDAS/GTS NUMERICAL SIMULATION}

\section{Selection of Model Parameters}

Through the research achievements at present loose accumulation of soil parameters, combined with the Sichuan Tibet highway south line field research results and the actual situation of the project, the value selection and fix the parameters of slope soil,as show in table 1.

Table 1. Reference Value of Soil Parameters

\begin{tabular}{|c|c|c|c|c|c|c|c|}
\hline Category & $\begin{array}{c}\text { Elstic } \\
\text { Modulus } \\
\text { E/MPa }\end{array}$ & $\begin{array}{c}\text { Poisson } \\
\text { Ratio } \\
\mu\end{array}$ & $\begin{array}{c}\text { Bulk } \\
\text { Density } \\
\gamma / \mathrm{KN} / \mathrm{m} 3\end{array}$ & $\begin{array}{c}\text { Saturated } \\
\text { Unit } \\
\text { Weight } \\
\gamma_{\text {sat }} / \mathrm{KN} / \mathrm{m} 3\end{array}$ & $\begin{array}{c}\text { Water } \\
\text { Content } \\
\omega / \%\end{array}$ & $\begin{array}{c}\text { Internal } \\
\text { Friction } \\
\text { Angle } \\
\varphi / \mathrm{o} \\
\end{array}$ & $\begin{array}{c}\text { Cohesive } \\
\text { Strength } \\
\mathrm{C} / \mathrm{kPa}\end{array}$ \\
\hline Numerical & 98.43 & 0.3 & 17.5 & 18.7 & 16.72 & 36.4 & 40.6 \\
\hline
\end{tabular}

\section{Geometric Modeling and Meshing}

In the Midas/GTS interface, the Moore Kulun model is chosen to establish the corresponding 
geometric model of the slope, the grid size is defined as 0.8. Choose two slope, each level height is $4 \mathrm{~m}$, set the $2 \mathrm{~m}$ platform in the middle of the two stage of slope and slope length is $8 \mathrm{~m}$, slope horizontal gradient of 1:0.5,1:0.75,1:1,1:1.25,1:1.5. for the five standards, followed by combination of uphill and downhill assignment. The grid of the slope is shown in Figure 1.

\section{Define Boundary Conditions}

The selection of support, that is, the choice of the slope of the lateral constraints, to the two sides, the bottom and the back of a total of four surface constraints,as show in figure 2.

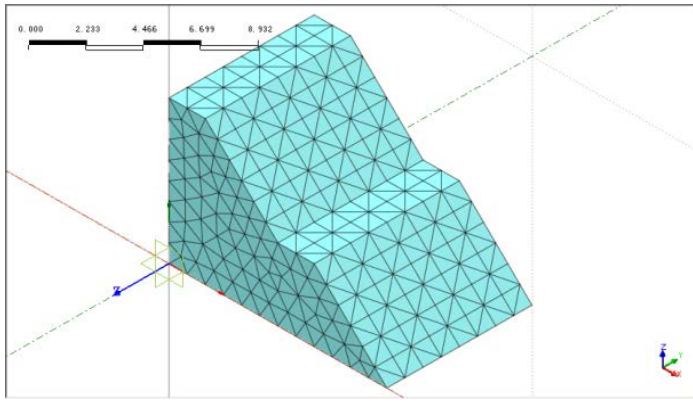

FIGURE1.Schematic Diagram of Graded Slope

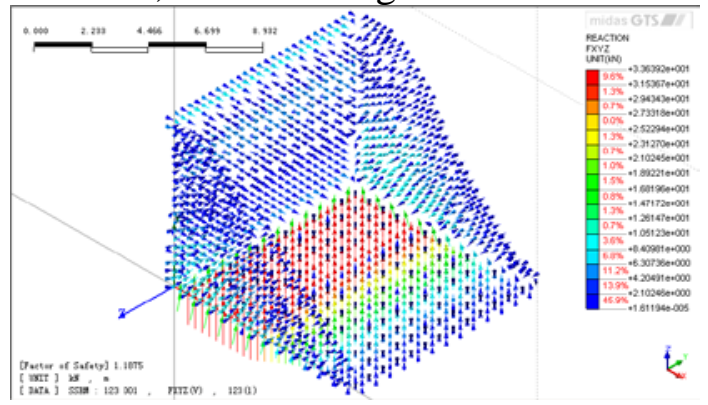

FIGURE2.Slope Model Boundary

\section{NUMERICAL ANALYSIS OF SLOPE STABILITY}

\section{Definition of Slope Safety Factor}

The safety factor of slope stability is defined as the ratio of the shear strength to the slip surface, the formula is

$$
K=\frac{\int(c+\sigma \tan \varphi) d A}{\int \tau d A}
$$

Three dimensional finite element analysis of the strength reduction method and failure criteria (1) on both sides of the same divided by $K$, the formula is

$$
1=\frac{\int\left(\frac{c}{K}+\frac{\sigma}{K} \tan \varphi\right) d A}{\int \tau d A}=\frac{\int\left(c^{\prime}+\sigma \tan \varphi^{\prime}\right) d A}{\int \tau d A}
$$

In formula,

$$
c^{\prime}=\frac{c}{K} \quad \varphi^{\prime}=\operatorname{arccot}\left(\frac{\tan \varphi}{K}\right)
$$

By gradually adjusting the coefficient $K$, Calculate different $c^{\prime}, \varphi^{\prime}$, take $c^{\prime}$ and $\varphi^{\prime}$ into the finite element program, repeated analysis of the slope until the slope reached the critical state, the slope of the critical state of the $K$ value as the slope stability safety factor.

\section{Safety Factor of Single Slope with Same Slope Height}

Through numerical calculation, the safety factor of the corresponding single slope can be obtained and is shown in table 2.

Table 2.Safety Factor of The Slope of ASingle Slope

\begin{tabular}{cccccc} 
Gradient & $1: 0.5$ & $1: 0.75$ & $1: 1$ & $1: 1.25$ & $1: 1.5$ \\
\hline $\begin{array}{l}\text { Safety } \\
\text { Factor }\end{array}$ & 1.1125 & 1.2375 & 1.3375 & 1.3725 & 1.6375 \\
\hline
\end{tabular}


Through the numerical calculation, the safety factor of the two slope with changed single slope ratio is shown in table 3 .

Table 3.Variable Slope Safety Factor of Two Slope

\begin{tabular}{cccccc}
\hline $\begin{array}{c}\text { Hygher } \\
\text { Lothigher Safety Slpoe } \\
\text { Slpoe }\end{array}$ Factor & $1: 0.5$ & $1: 0.75$ & $1: 1$ & $1: 1.25$ & $1: 1.5$ \\
\hline $1: 0.5$ & 1.3125 & 1.3125 & 1.3375 & 1.4125 & 1.4375 \\
$1: 0.75$ & 1.4375 & 1.4375 & 1.4725 & 1.5125 & 1.5375 \\
$1: 1$ & 1.5125 & 1.5125 & 1.5375 & 1.5625 & 1.6125 \\
$1: 1.25$ & 1.5875 & 1.6125 & 1.6375 & 1.6725 & 1.7025 \\
$1: 1.5$ & 1.7125 & 1.7375 & 1.7625 & 1.8125 & 1.8375 \\
\hline
\end{tabular}

In order to reflect the effect of changing the slope on the slope stability, the change of slope stability,draw the change trend of slope stability,as show in figure 3 and figure 4.

It is shown in figure 3andfigure 4that under the same slope ratio conditions, two levels of safety coefficient of slope was significantly higher than that of single slope. At the same time, the lower the same slope conditions, with higher slope slow, safety coefficient of slope increases gradually, but the increase is relatively smooth. On the same level of slope conditions. With the lower slope safety coefficient of slope body becomes gradually increased, but compared with the higher slope changes for affecting the safety coefficient of slope, resulting in lower slope safety coefficient of slope change is more obvious.

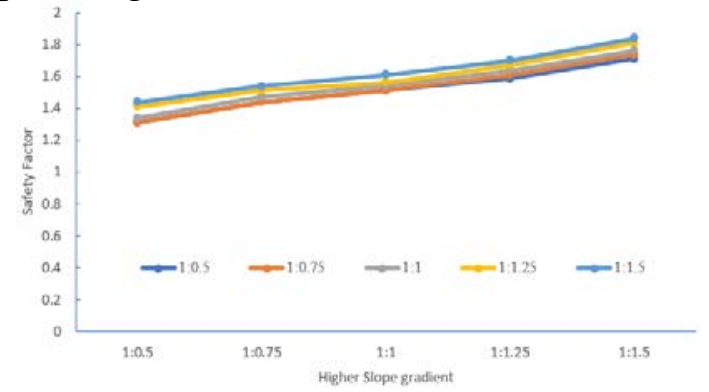

FIGURE3.Slope Safety Factor Changes with Higher Slope Gradient

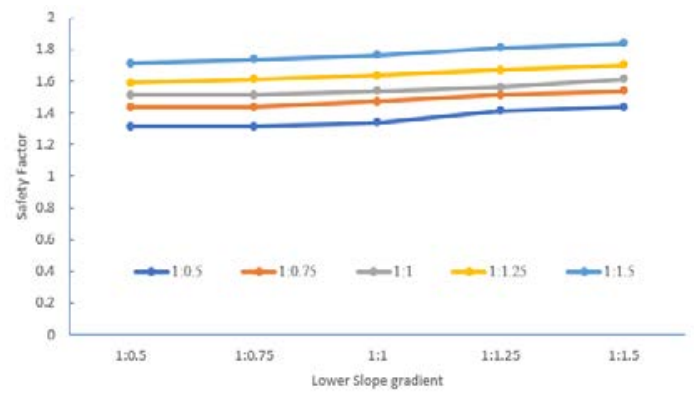

FIGURE4.Slope Safety Factor Changes with Lower Slope Gradient

\section{CONCLUSION}

The slope stability can be improved obviously by the graded slope, and the influence of the lower slope gradient on the slope safety factor is greater than that of the upper slope.Therefore, try to take the hierarchical slope form in the south section of Sichuan Tibet highway subgrade slope design and construction. Take the hierarchical slope, try to slow down under the slope, slope slope can be determined according to the local geological conditions and engineering construction conditions, take a combination of reasonable slope, can be achieved according to local conditions, reasonable allocation, saving the cost.

\section{ACKNOWLEDGMENTS}

This work was financially supported by National Science and Science Technology fund. The project name are Study on Deformation Characteristics of Loose Accumulation Subgrade based on Hydraulic Coupling Mechanism (project number: 310821162012)and Strong Weathering Phyllite Filling Road Based Water Stress Coupling and Long-term Deformation Characteristics Research(project number: 211021130246). 


\section{REFERENCES}

[1] MAO Xuesong, WANG Nan, GAO Shengyu, et al. Loose deposits types along the south line of Sichuan-Tibet(in Tibet) highway[J]. Journal of Chang'an University(Natural Science Edition), 2014,34 (5): 8-14.

[2] Li Jia chun, Huang Li zhen, Tian Wei ping, et al.Type classification on natural disasters of highway[J]. Journal of Chang'an University(Natural Science Edition), 2011,31 (2): 33-37.

[3] ZHANG Jiqing. Reasearch on Stability Analysis and Treatment technology of the Impact Deposit Soil Cutting Slope of SHI Zhong Highway[D].Chong Qing Jiao Tong U niversity,2009.

[4] ZHAO Jianjun,JU Nengpan,TU Guoxiang.Deformation Michanism and Supporting Measures of Manmade Slopes in Loose Deposits[J].Journal of Engineering Geology, 2000, 16(5): 611-615.

[5] MIAOHaibo,YIN Kunlong,XING Linxiao,et al.Evolution analysis of loose debris slope under condition of extreme snow hazard[J]. Rock and Soil Mechanics, 2012, 33(1):147- 153. 